demonstrate continuous quality improvement. They have provided a route to build quality improvement methodology as part of the hospice's culture, whilst ensuring connection with the hospice strategy.

\section{P-268 TEAM BUILDING, HEALTHY WORKPLACE, HEALTHY YOU}

Michelle Holgate, Christine Johnson, Sarah Williams. Garden House Hospice Care, Letchworth, UK

\subsection{6/bmjspcare-2019-HUKNC.290}

Background Over the last two years the Inpatient Unit (IPU) has seen a significant change in leadership and nursing staff. It was recognised that there was a need to encourage willingness to accept change and promote teamwork. Research by Maben et al (2012) shows that patient experiences are generally better when staff feel they have a good team climate, colleague support, as well as job satisfaction and a positive organisational culture. As a result of this it was decided that team-building workshops would be held.

Aims

- Act as a forum for individuals and teams to reflect on their own behaviour

- Help to produce a supportive culture where bullying and harassment are unlikely to occur

- Encourage positive behaviour

- Discourage negative behaviour

- Increase understanding of behaviour that may be perceived to be bullying or harassment whether intended or not

- Increase acceptance of strategies that might be used to retrieve a problem situation.

Method Four workshops were held. IPU staff were invited to the workshops which were structured around the RCN Toolkit 'Healthy Workplace, Healthy You' (2015). This includes selfassessment forms where participants can reflect on their behaviour and attitudes. Participants then completed a team assessment form in which they reflect on the attitudes, behaviours and culture within the team.

Results An action plan was devised as a group to address identified issues. The toolkit provides a measurable outcome of how staff are feeling which will be repeated at future dates to give demonstrable progress.

Conclusions

- Feedback has been positive. Staff voiced that the workshops provided a calm and supportive forum to discuss any issues within the team

- Staff had the opportunity to reflect on positives within the team

- An action plan was agreed and will be reviewed regularly as well as at the next full 'Team Away' Day.

\section{P-269 CREATE 2020 - A REVIEW OF OUR ORGANISATIONAL CULTURE. TAKING LOROS 'FROM GOOD TO GREAT'}

Danielle Smeeton, John Knight. LOROS Hospice, Leicester, UK

10.1136/bmjspcare-2019-HUKNC.291

Background In 2018 senior leaders at LOROS decided to undertake a review of our organisational culture in order to gain a better understanding of what matters most to staff and volunteers. Clearly understanding how the culture 'feels' now, provides the benchmark that enables us to improve how it 'feels' in the future. This in turn, would improve not only the experience of our staff and volunteers but also underpins our ability to deliver excellent end of life care, for patients and families.

Aims

- To undertake an independent review of our organisational culture;

- To identify actions that need to be addressed in order for us to build upon what is already good about LOROS culture;

- To create a group of 'Culture Champions' offering approachable support for our staff and volunteers;

- To progress work that emerges from the review.

Methods We commissioned an independent organisation (POD) to undertake a review of our current culture. POD consulted with 123 staff and volunteers via pre-arranged workshops which generated 1,800, anonymised comments, about our current culture. POD then created a report, based only on areas that we needed to improve. This was openly circulated to all staff and volunteers.

Results The report highlighted themes that became the 12 work streams for the Culture Champions. Their clear intention remains to improve those key areas of our culture. A member of the Senior Management Committee was also assigned, to assist with each area.

Conclusion Some work streams are complete and some are still ongoing. We have made many changes, as a result of the review e.g. revisiting the organisational values and using the new version throughout our everyday work. All work will be completed by 2020 , at which point a follow up cultural survey will be commissioned.

\section{P-270 IMPLEMENTING PERSON-CENTRED PRACTICE IN A HOSPICE}

Anne Howard, Diane Barker. Marie Curie Hospice, Liverpool, UK

\subsection{6/bmjspcare-2019-HUKNC.292}

Person-centred practice is increasingly being adopted within health care and aims to facilitate true partnership working between service users and health professionals (Ewing, Austin, Diffin \& Grande, 2015)). There is an increasing body of evidence that person-centred practice can improve health outcomes, quality of care, and patient experience (Collins, 2014). However, person-centeredness can only happen if there is an appropriate culture (McCormack et al., 2008).

In partnership with Queen Margaret's University, Edinburgh, Marie Curie committed to the development of PersonCentred cultures throughout their caring services. In 2016 the Marie Curie Hospice Liverpool embarked on this journey using McCormack and McCance (2010) Person-Centred Framework for Practice. A multidisciplinary steering group was established. Values clarification, and action learning sets led to the development of a Person-Centred vision for the hospice.

This collaborative vision formed the basis of evaluative work which benchmarked our culture in relation to the vision. Alongside the framework, a variety of tools were used 